\title{
Homocysteine Elicits a DNA Damage Response in Neurons That Promotes Apoptosis and Hypersensitivity to Excitotoxicity
}

\author{
Inna I. Kruman, ${ }^{1}$ Carsten Culmsee, ${ }^{2}$ Sic L. Chan, ${ }^{1}$ Yuri Kruman, ${ }^{1}$ Zhihong Guo, ${ }^{1}$ LaRoy Penix, ${ }^{2}$ \\ and Mark P. Mattson ${ }^{1,2}$ \\ 1 Laboratory of Neurosciences, National Institute on Aging, Baltimore, Maryland 21224, and ${ }^{2}$ Sanders-Brown Research \\ Center on Aging and Department of Anatomy and Neurobiology, University of Kentucky, Lexington, Kentucky 40536
}

\begin{abstract}
Elevated plasma levels of the sulfur-containing amino acid homocysteine increase the risk for atherosclerosis, stroke, and possibly Alzheimer's disease, but the underlying mechanisms are unknown. We now report that homocysteine induces apoptosis in rat hippocampal neurons. DNA strand breaks and associated activation of poly-ADP-ribose polymerase (PARP) and NAD depletion occur rapidly after exposure to homocysteine and precede mitochondrial dysfunction, oxidative stress, and caspase activation. The PARP inhibitor 3-aminobenzamide (3AB) protects neurons against homocysteine-induced NAD depletion, loss of mitochondrial transmembrane potential, and cell death, demon-
\end{abstract}

strating a requirement for PARP activation and/or NAD depletion in homocysteine-induced apoptosis. Caspase inhibition accelerates the loss of mitochondrial potential and shifts the mode of cell death to necrosis; inhibition of PARP with $3 A B$ attenuates this effect of caspase inhibition. Homocysteine markedly increases the vulnerability of hippocampal neurons to excitotoxic and oxidative injury in cell culture and in vivo, suggesting a mechanism by which homocysteine may contribute to the pathogenesis of neurodegenerative disorders.

Key words: calcium; caspase; mitochondrial transmembrane potential; NAD; PARP; stroke
The risk for coronary artery disease (Refsum et al., 1998), stroke (Elkind and Sacco, 1998), and possibly Alzheimer's disease (Clarke et al., 1998; Miller, 1999) is increased in individuals with an elevated plasma homocysteine concentration. Homocysteine is a metabolite of the essential amino acid methionine. Methionine plays a key role in the generation of methyl groups required for the synthesis of DNA, and homocysteine can be either remethylated to methionine by enzymes that require folate or cobalamin (vitamin $\mathrm{B} 12)$ or catabolized by cystathionine $\beta$-synthase, a pyridoxine (vitamin B6)-dependent enzyme, to form cysteine (Finkelstein, 1990; Scott and Weir, 1998). Homocysteine levels vary considerably among individuals, and reduced dietary intake of folate is associated with increased homocysteine levels and increased risk for heart disease and stroke (Giles et al., 1995). In addition, folate deficiency can cause DNA damage that may result from hypomethylation. Patients with severe hyperhomocysteinemia exhibit a wide range of clinical manifestations including neurological abnormalities such as mental retardation, cerebral atrophy, and seizures (Watkins and Rosenblatt, 1989; van den Berg et al., 1995). It is not known whether neurological damage in these patients results from a direct action on neurons or is secondary to vascular changes. Moreover, although studies of atherosclerosis suggest a role for increased oxidative stress in the damage to vascular endothelial cells by homocysteine (Wall et al., 1980; Starkebaum and Harlan, 1986; Blundell et al., 1996), the cellular and molecular mechanism(s) underlying the adverse effects of homocysteine is unknown.

Increasing data suggest that neurons may die by a form of programmed cell death called apoptosis in a range of neurodegenerative conditions including Alzheimer's disease (Su et al., 1994; Mattson et al., 1999) and stroke (Linnik et al., 1993; Dirnagl et al., 1999). Although a variety of initiating factors may contribute to such cell deaths, they appear to involve a shared biochemical cascade involving oxidative stress, overactivation of glutamate re-

Received March 16, 2000; revised June 21, 2000; accepted July 6, 2000.

This work was supported by the National Institute on Aging. We thank M. Juhasova and M. Killen for technical assistance.

Correspondence should be addressed to Dr. Mark P. Mattson, Laboratory of Neurosciences, National Institute on Aging Gerontology Research Center, 5600 Nathan Shock Drive, Baltimore, MD 21224. E-mail: mattsonm@grc.nia.nih.gov.

Copyright (C) 2000 Society for Neuroscience 0270-6474/00/206920-07\$15.00/0 ceptors, activation of caspases, and mitochondrial dysfunction. DNA damage has been documented in Alzheimer's disease and stroke patients (Love et al., 1998; Torp et al., 1998; Adamec et al., 1999) and in experimental models of these disorders (Bozner et al., 1997; Hou et al., 1997). DNA damage in neurons may trigger a cell death cascade involving activation of poly-ADP-ribose polymerase (PARP) (for review, see Pieper et al., 1999) and induction of the tumor suppressor protein p53 (for review, see Hughes et al., 1997). We now report that homocysteine can induce neuronal apoptosis and can increase neuronal vulnerability to excitotoxicity by a mechanism involving DNA damage, PARP activation, and p53 induction.

\section{MATERIALS AND METHODS}

Hippocampal cell cultures and experimental treatments. Primary hippocampal cell cultures were established from embryonic day 18 rat embryos by the use of methods described previously (Mattson et al., 1989). Dissociated cells were seeded onto polyethyleneimine-coated plastic dishes or $22 \mathrm{~mm}^{2}$ glass coverslips and incubated in Neurobasal medium containing B-27 supplements, $2 \mathrm{~mm}$ L-glutamine, $25 \mu \mathrm{g} / \mathrm{ml}$ gentamycin, and $1 \mathrm{~mm}$ HEPES with $0.001 \%$ gentamycin sulfate. All experiments were performed with 7to 9 -d-old cultures, at which time the cultures contain $\sim 90-95 \%$ neurons and $5-10 \%$ astrocytes. The neurons in these cultures express both NMDA and non-NMDA glutamate receptors and are vulnerable to excitotoxicity and apoptosis induced by various insults (Mattson et al., 1989; Kruman et al., 1997; Furukawa and Mattson, 1998). Experimental treatments were added to cultures by dilution into the culture maintenance medium from concentrated $(200-500 \times)$ stocks. Homocysteine, glutamate, 3-aminobenzamide $(3 \mathrm{AB}), \mathrm{FeSO}_{4}$, and $\mathrm{CuSO}_{4}$ (Sigma, St. Louis, $\mathrm{MO}$ ) were prepared as concentrated stocks in sterile water, $\mathrm{pH}$ 7.2. Concentrated stocks of $N$-benzyloxycarbonyl-Val-Ala-Asp-fluoromethyl ketone (zVAD-fmk; Calbiochem, La Jolla, CA) and 4-hydroxynonenal (Cayman Chemical, Ann Arbor, MI) were prepared in dimethylsulfoxide.

Assessments of DNA damage, apoptosis, and necrosis. DNA damage was assessed by the use of the "comet" assay (Trevigen) according to the manufacturer's protocol. The comet assay has been shown to be a sensitive and reliable measure of DNA strand breaks (Morris et al., 1999). To quantify apoptosis, cells were fixed in $4 \%$ paraformaldehyde and stained with the fluorescent DNA-binding dye Hoechst 33342 as described previously (Kruman et al., 1997). Hoechst-stained cells were visualized and photographed under epifluorescence illumination (340 nm excitation and $510 \mathrm{~nm}$ barrier filter) using a $40 \times$ oil immersion objective $(200$ cells/culture were counted, and counts were made in at least four separate cultures/ treatment condition). Analyses were performed without knowledge of the treatment history of the cultures. The percentage of "apoptotic" cells (cells with condensed and fragmented nuclear chromatin were considered apoptotic) in each culture was determined. Necrotic neurons were identified by 


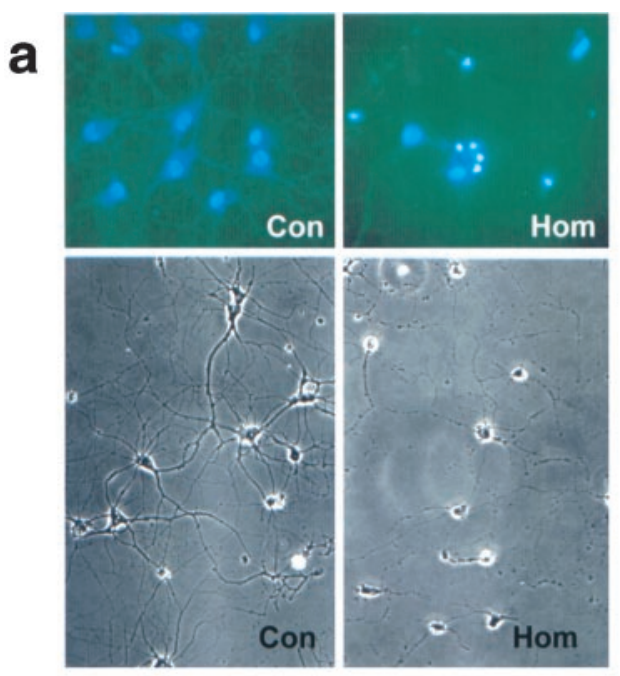

C

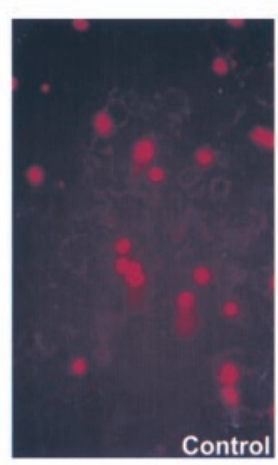

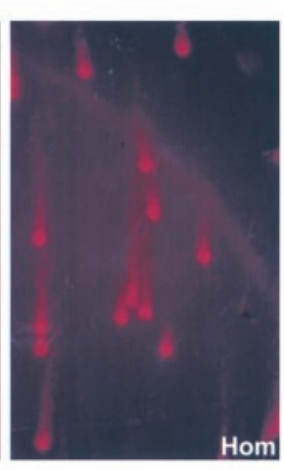

b

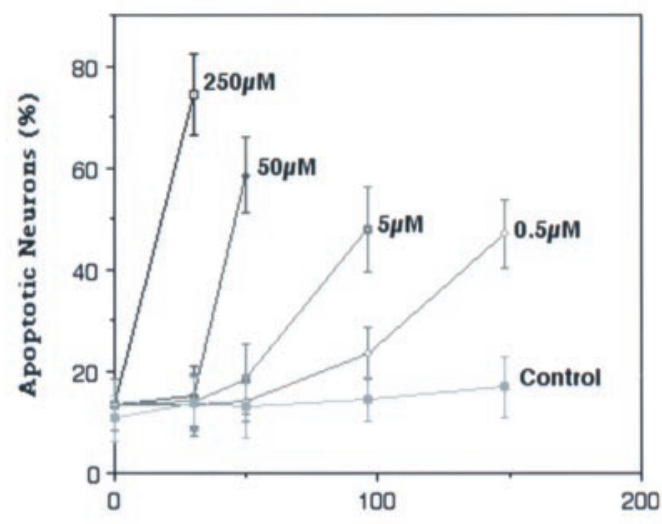

Time (hr)
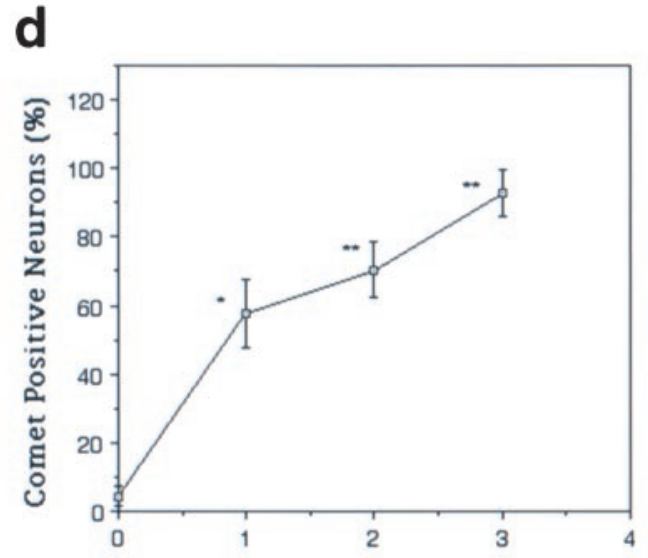

Figure 1. Homocysteine induces DNA damage and apoptosis in cultured hippocampal neurons. $a$, Cultures were exposed for $28 \mathrm{hr}$ to either saline (Con) or $250 \mu \mathrm{M}$ homocysteine (Hom) and then were stained with the fluorescent DNAbinding dye Hoechst 33342 (top) or were photographed under phase-contrast optics (bottom). Note the nuclear DNA condensation and fragmentation and the damage to neurites in many of the neurons in the culture exposed to homocysteine. $b$, Cultures were exposed to the indicated concentrations of homocysteine for the indicated time periods, and the percentages of neurons with apoptotic nuclei were quantified. Values are the mean and SD of determinations made in four to six cultures. $c$, Comet assay analysis of nuclear DNA in neurons in a control culture (left) and a culture that had been exposed for $1 \mathrm{hr}$ to $250 \mu \mathrm{M}$ homocysteine is shown. Note the comet-like appearance of DNA in the neurons that had been exposed to homocysteine. $d$, Cultures were exposed to $250 \mu \mathrm{M}$ homocysteine for the indicated time periods, and comet assays were performed. Values are the mean and SD of determinations made in four cultures. ${ }^{*} p<0.01$ and ${ }^{* *} p<0.001$ compared with the basal value (ANOVA with Scheffe post hoc tests).

increased plasma membrane permeability as indicated by their uptake of the dye trypan blue, although it should be noted that cells in the late stages of apoptosis may also exhibit membrane permeability changes that would allow trypan blue uptake.

Measurement of PARP activity, NAD+ levels, caspase activity, and p53 levels. PARP activity levels were quantified as described previously (Hinshaw et al., 1999). Briefly, after experimental treatment, cells were washed with cold PBS and then incubated in a buffer consisting of $28 \mathrm{~mm} \mathrm{NaCl}, 28$ $\mathrm{mm} \mathrm{KCl}, 2 \mathrm{~mm} \mathrm{MgCl}, 0.01 \%$ digitonin, $125 \mathrm{~nm}$ NAD, $0.25 \mu \mathrm{Ci} / \mathrm{ml}$ $\left[{ }^{3} \mathrm{H}\right] \mathrm{NAD}$, and $56 \mathrm{~mm}$ HEPES, $\mathrm{pH} 7.5$. After a $5 \mathrm{~min}$ incubation at $37^{\circ} \mathrm{C}$ ADP-ribosylated protein was precipitated with $50 \%$ trichloroacetic acid (TCA). After washing with TCA, the protein pellet was solubilized in $2 \%$ SDS in $0.1 \mathrm{M} \mathrm{NaOH}$, and radioactivity was quantified by scintillation counting. Values were normalized to the protein content. NAD+ levels were quantified by an enzymatic cycling technique that used alcohol dehydrogenase from Saccharomyces cerevisiae as described previously (Bernofsky and Swan, 1973). Briefly, NAD + was extracted by adding cold $\mathrm{HClO}_{4}$ to the cell cultures. After a $15 \mathrm{~min}$ incubation at $4^{\circ} \mathrm{C}$, cell extracts were neutralized by incubation for $15 \mathrm{~min}$ with an equal volume of a solution containing $1 \mathrm{M} \mathrm{KOH}$ and $0.33 \mathrm{M} \mathrm{KH}_{2} \mathrm{PO}_{4}$, pH 7.5. Samples were centrifuged at $1500 \times g$ for 5 min. NAD+ levels in the supernatant were estimated by the use of the NAD + reaction mixture that consisted of 600 mM ethanol, $0.5 \mathrm{~mm} 3[4,5$ dimethylthiazol-2-yl]-2,5-diphenyltetrazolium bromide, $2 \mathrm{~mm}$ phenazine ethosulfate, $5 \mathrm{~mm}$ EDTA, $1 \mathrm{mg} / \mathrm{ml} \mathrm{BSA}$, and $120 \mathrm{~mm}$ bicine, $\mathrm{pH} 7.8$. The reaction was initiated by addition of $0.1 \mathrm{ml}$ of alcohol dehydrogenase $(0.5 \mathrm{mg} / \mathrm{ml}$ in $100 \mathrm{~mm}$ bicine, $\mathrm{pH} 7.8)$. The reaction was stopped by adding $12 \mathrm{~mm}$ iodoacetate. Optical densities were measured spectrophotometrically at $570 \mathrm{~nm}$, and values were normalized to the protein content

Caspase-3-like protease activity was assessed in cultured neurons by the use of a method described previously (Mattson et al., 1998) that uses DEVD, a pseudosubstrate and inhibitor of caspase-3. At designated time points after experimental treatment, cells were incubated for $10 \mathrm{~min}$ in Locke's buffer containing $0.01 \%$ digitonin. Cells were then incubated for $20 \mathrm{~min}$ in the presence of $10 \mu \mathrm{g} / \mathrm{ml}$ biotinylated DEVD-CHO (Calbiochem), washed three times with PBS ( $2 \mathrm{ml} /$ wash $)$, and fixed for $30 \mathrm{~min}$ in a cold solution of $4 \%$ paraformaldehyde in PBS. Cells were then incubated for $5 \mathrm{~min}$ in PBS containing $0.2 \%$ Triton $\mathrm{X}-100$, followed by a $30 \mathrm{~min}$ incubation in PBS containing $5 \mu \mathrm{g} / \mathrm{ml}$ Oregon Green-Streptavidin (Molecular Probes, Eugene, OR). Cells were then washed twice with PBS, and images of fluorescence (corresponding to conjugates of activated caspase-3 with DEVD-biotin) were acquired by the use of a confocal laser-scanning microscope. Levels of fluorescence in neuronal cell bodies were quantified with Imagespace software (Molecular Probes) as described previously (Mattson et al., 1998). To measure relative levels of p53, cultures were immunostained with a p53 antibody (1:2000 dilution of rabbit polyclonal antibody specific for p53 phosphorylated on serine 15; New England Biolabs, Beverly, MA) by the use of an indirect immunofluorescence method. Confocal laser-scanning microscope images of stained cells were acquired, and relative levels of immunoreactivity (average pixel intensity/ neuron) were quantified as described previously (Mattson et al., 1997).

Measurement of mitochondrial oxyradical levels and transmembrane potential. The dye dihydrorhodamine (DHR), which enters mitochondria and fluoresces when oxidized by reactive oxygen species (particularly peroxynitrite and the hydroxyl radical) to the positively charged rhodamine 123 derivative, was used to measure relative levels of mitochondrial oxyradicals as described (Mattson et al., 1997). After experimental treatment, cells were incubated for $30 \mathrm{~min}$ in the presence of $10 \mu \mathrm{M}$ DHR and then were washed twice in Locke's buffer. DHR fluorescence was imaged by the use of a confocal laser-scanning microscope with excitation at $488 \mathrm{~nm}$ and emission at $510 \mathrm{~nm}$, and the average pixel intensity in neuronal cell bodies was determined with Imagespace software (Molecular Dynamics). All images were coded and analyzed without knowledge of the experimental treatment history of the cultures. Mitochondrial transmembrane potential was assessed by the use of the dye $5,5^{\prime}, 6,6^{\prime}$-tetrachloro- $1,1^{\prime}, 3,3^{\prime}$-tetraethylbenzimidazolocarbocyanine iodide (JC-1) by methods similar to those described previously (White and Reynolds, 1996). Briefly, cells were incubated for $30 \mathrm{~min}$ in the presence of $5 \mu \mathrm{M}$ dye and washed twice with Locke's buffer, and fluorescence was quantified by the use of a fluorescence plate reader.

Measurement of intracellular $\mathrm{Ca}^{2+}$ levels. Intracellular free $\mathrm{Ca}^{2+}$ levels were quantified by fluorescence ratio imaging of the calcium indicator dye fura-2 using methods described previously (Cheng et al., 1994). Briefly, cells were loaded with the acetoxymethyl ester form of fura-2 (30 min 
incubation in the presence of $10 \mu \mathrm{M}$ fura-2) and imaged using a Zeiss AttoFluor system with a $40 \times$ oil objective. The average $\left[\mathrm{Ca}^{2+}\right]_{i}$ in individual neuronal cell bodies was determined from the ratio of the fluorescence emissions obtained with two different excitation wavelengths (334 and $380 \mathrm{~nm}$ ). The system was calibrated with solutions containing either no $\mathrm{Ca}^{2+}$ or a saturating level of $\mathrm{Ca}^{2+}(1 \mathrm{mM})$ by the use of the formula: $\left[\mathrm{Ca}^{2+}\right]_{\mathrm{i}}=K \mathrm{~d}\left[\left(R-R_{\min }\right) /\left(R_{\max }-R\right)\right]\left(F_{0} / F_{\mathrm{s}}\right)$.

In vivo studies. Experiments were performed in 3-month-old male C57BL/6 mice (25-30 gm body weight) obtained from the National Cancer Institute. Mice were divided into five groups $(6-8$ mice/group): saline control, kainate $(0.2 \mu \mathrm{g})$ alone, high-dose homocysteine $(4.3 \mathrm{ng})$ alone, kainate plus low-dose homocysteine $(0.43 \mathrm{ng})$, and kainate plus high-dose homocysteine. Kainate and homocysteine were administered via stereotaxic injection into the dorsal hippocampus by the use of methods described previously (Bruce et al., 1996). Briefly, kainate and homocysteine (1 $\mu$ l volume) were injected unilaterally into the dorsal hippocampus (dorsoventral, -1.8; mediolateral, +2.4 ; and anteroposterior, -2.0 from bregma) of mice anesthetized with chloral hydrate $(350 \mathrm{mg} / \mathrm{kg})$ and xylazine $(4 \mathrm{mg} / \mathrm{kg})$. Twenty-four hours later mice were anesthetized with halothane and perfused transcardially with saline followed by cold phosphate-buffered $4 \%$ paraformaldehyde. Coronal brain sections were cut on a freezing microtome and stained with cresyl violet. Nissl-positive undamaged neurons were counted in three $40 \times$ fields in region CA3 of both the ipsilateral and contralateral hippocampus of each mouse. Counts were made in five coronal brain sections per mouse (sections were chosen by unbiased sampling), and the mean number of cells per section were determined such that the value obtained for each mouse represents an average total number of neurons counted per section (i.e., sum of six $40 \times$ fields for each hippocampal region). Comparisons of numbers of undamaged neurons in hippocampal regions among treatment groups were made with ANOVA followed by Scheffe tests for pairwise comparisons.

\section{RESULTS}

Because the hippocampus is a brain region that can be selectively damaged in disorders associated with increased homocysteine levels (stroke, epileptic seizures, and Alzheimer's disease) (Squire and Zola, 1996; Morrison and Hof, 1997; Houser, 1999), we per- formed a series of experiments aimed at establishing whether and how homocysteine might damage hippocampal neurons. Exposure of primary hippocampal neurons to homocysteine resulted in apoptosis, the time course of which was inversely related to homocysteine concentration (Fig. 1a,b). Whereas $250 \mu \mathrm{M}$ homocysteine induced apoptosis in nearly all neurons within $28 \mathrm{hr}$, exposure to $0.5 \mu \mathrm{M}$ resulted in delayed apoptosis that became apparent at $4 \mathrm{~d}$ and progressed through $6 \mathrm{~d}$. DNA strand breaks, detected by comet assay, occurred very rapidly in neurons exposed to homocysteine, with numerous comet-positive neurons being observed within $1 \mathrm{hr}$ of exposure to $250 \mu \mathrm{M}$ homocysteine (Fig. 1c,d). Neurons appear selectively vulnerable to homocysteine-induced apoptosis because astrocytes and cultured vascular endothelial cells were not killed during 3-6 d exposures to millimolar concentrations of homocysteine (data not shown).

Poly-ADP-ribose polymerase is a DNA repair enzyme selectively activated by DNA strand breaks that catalyzes the addition of long branched chains of poly-ADP-ribose from its substrate NAD + to a variety of nuclear proteins (Pieper et al., 1999). High levels of PARP activity can decrease NAD + levels and thereby deplete ATP resulting in cell death. Homocysteine induced a rapid twofold increase in PARP activity that occurred within 1-2 hr of exposure and then subsequently decreased during the next $2 \mathrm{hr}$ (Fig. 2a). NAD+ levels were significantly decreased within $6 \mathrm{hr}$ of exposure of neurons to homocysteine and continued to decrease through 8 hr (Fig. $2 b$ ). The PARP inhibitor $3 \mathrm{AB}$ completely prevented NAD+ depletion after exposure to homocysteine (Fig. 2c). By inactivating PARP, cleavage of PARP by cysteine proteases of the caspase family is believed to play an important role in promoting apoptosis and preventing necrosis (Lazebnik et al., 1994). We

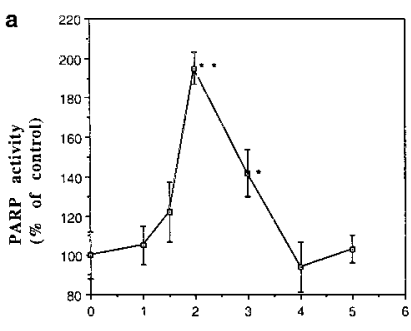

Time of exposure to Hom (hr)

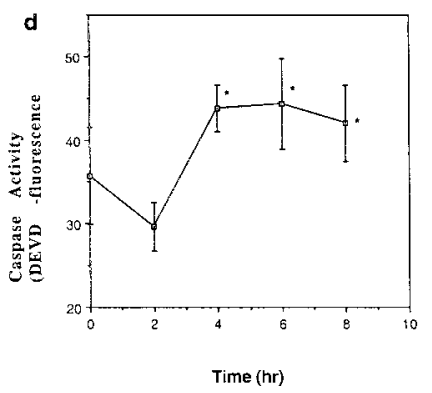

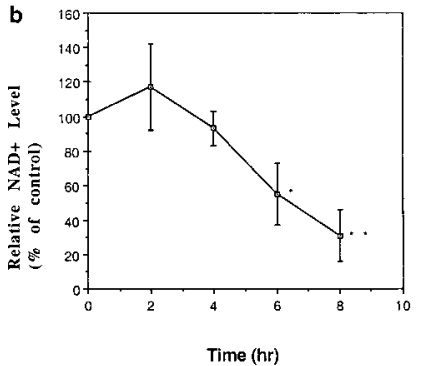
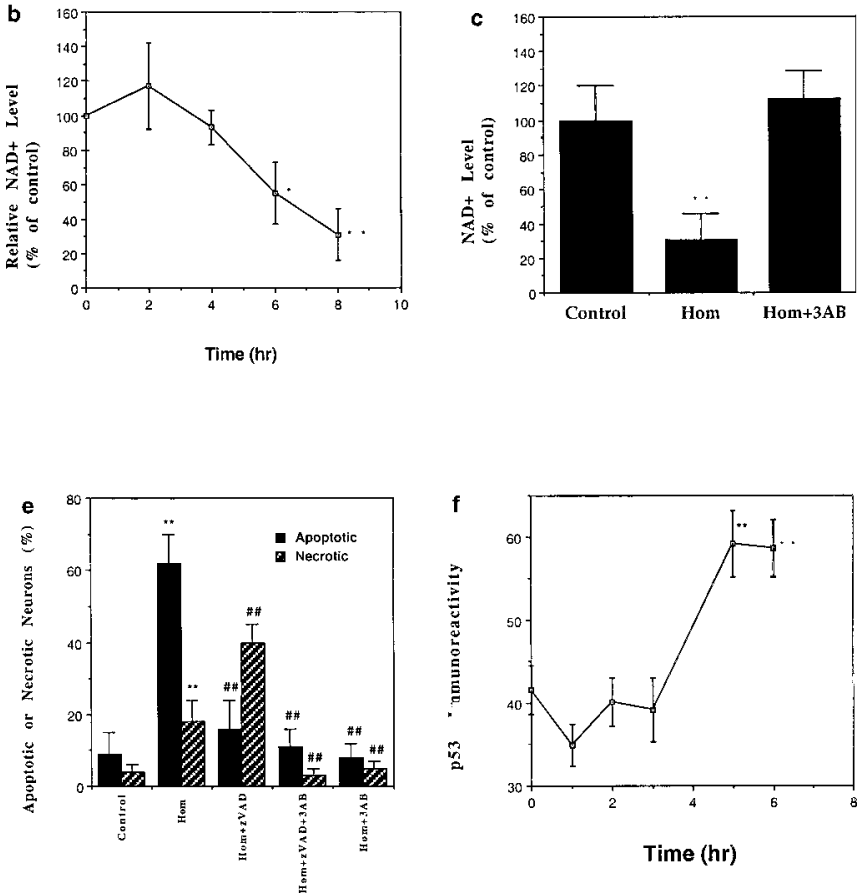

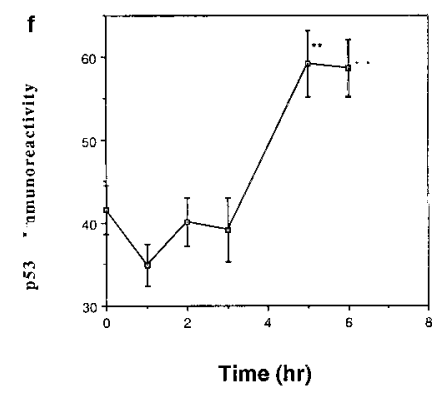

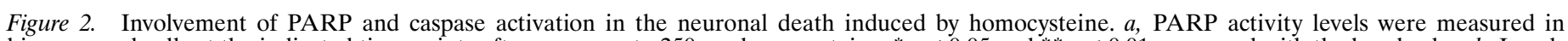

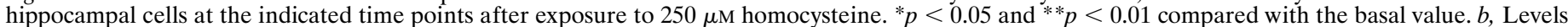

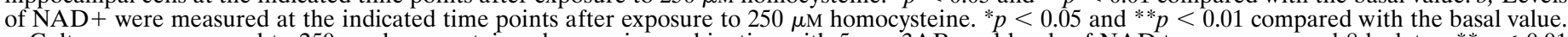

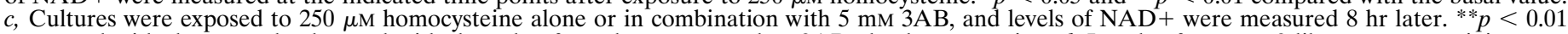

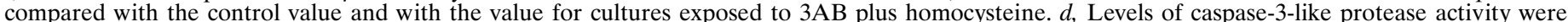

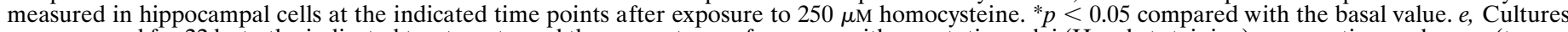

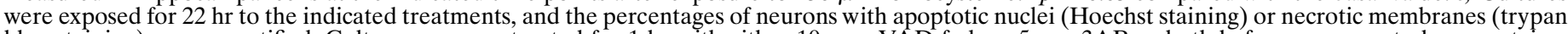

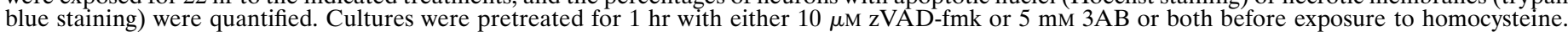

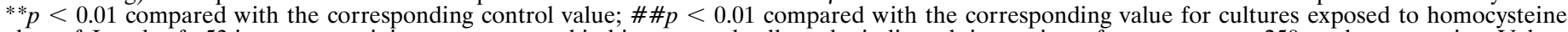

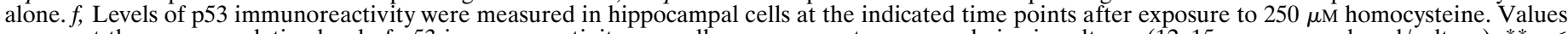

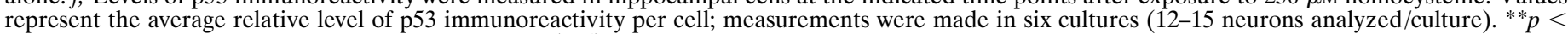

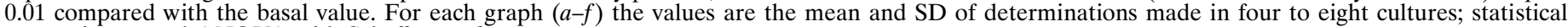
comparisons used ANOVA with Scheffe post hoc tests. 
found that levels of caspase-3-like protease activity increased significantly within $4 \mathrm{hr}$ of exposure of neurons to homocysteine (Fig. $2 d)$. Treatment of cultures with the broad-spectrum caspase inhibitor zVAD-fmk significantly decreased the percentage of neurons undergoing apoptosis after exposure to homocysteine (Fig. 2e). However, zVAD-fmk significantly increased the percentage of neurons that underwent necrosis, consistent with a role for PARP cleavage in suppressing necrosis and promoting apoptosis. Treatment of cultures with $3 \mathrm{AB}$ protected neurons exposed to homocysteine against both apoptotic and necrotic cell death (Fig. 2e), demonstrating a pivotal role for PARP activation in the cell death process. Treatment of neurons with 4-amino-1,8-naphtalimide, another PARP inhibitor, also significantly reduced neuronal death induced by homocysteine (data not shown).

The tumor suppressor protein p53 has been associated with apoptosis induced by DNA damage and in paradigms of neuronal apoptosis in which PARP is also involved (Cregan et al., 1999; Johnson et al., 1999). In addition, recent studies have linked increased p53 levels to neuronal degeneration in several disorders including Alzheimer's and Parkinson's diseases and amyotrophic lateral sclerosis (de la Monte et al., 1998). Exposure of hippocampal neurons to homocysteine resulted in a significant increase in the levels of activated p53 (detected by the use of an antibody that binds selectively to p53 phosphorylated on serine residue 15) that occurred within 3-5 hr (Fig. 2f), a time course consistent with a response to the DNA damage that was evident within 1-3 hr of exposure to homocysteine (Fig. $1 d$ ). The increase in p53 activation was significantly attenuated in neurons cotreated with $3 \mathrm{AB}$. Levels of p53 immunoreactivity (average pixel intensity per neuron) $6 \mathrm{hr}$ after experimental treatment were as follows: control, $19 \pm 7 ; 250$ $\mu \mathrm{M}$ homocysteine, $43 \pm 7 ; 5 \mathrm{~mm} 3 \mathrm{AB}$ plus $250 \mu \mathrm{M}$ homocysteine, $16 \pm 4(p<0.001$ compared with the value for neurons exposed to homocysteine alone); and $5 \mathrm{~mm} 3 \mathrm{AB}, 23 \pm 6$ (values are the mean and SD of determinations made in four separate cultures, with 20-30 neurons assessed per culture). These data demonstrate an important role for PARP in homocysteine-induced p53 activation.

Mitochondrial dysfunction and oxidative stress appear to be common convergence points in the neuronal death process induced by many different insults including trophic factor withdrawal, overactivation of glutamate receptors, ischemia, and exposure to amyloid $\beta$-peptide (Nicotera et al., 1997; Keller et al., 1998; Dirnagl et al., 1999; Guo et al., 1999). Levels of mitochondrial oxyradicals, measured with the probe dihydrorhodamine, increased within $5 \mathrm{hr}$ of exposure to homocysteine and remained elevated thereafter (Fig. 3a). Mitochondrial membrane potential, assessed with the fluorescent probe JC-1, remained constant for $12 \mathrm{hr}$ after homocysteine exposure and then decreased significantly by $15 \mathrm{hr}$ and remained depressed thereafter (Fig. $3 b$ ). When cultures were pretreated with $3 \mathrm{AB}$ before exposure to homocysteine, levels of mitochondrial oxyradicals did not increase, and mitochondrial membrane potential remained constant through at least $18 \mathrm{hr}$ of exposure (Fig. $3 c, d$ ). Collectively, these findings suggest that DNA damage and PARP activation are early events that are required for the subsequent oxidative stress, mitochondrial dysf unction, and cell death induced by homocysteine in neurons. Further supporting a key role for DNA damage in neuronal apoptosis induced by homocysteine, exposure of cortical synaptosomes (a preparation that lacks nuclear DNA) to homocysteine at concentrations up to $2 \mathrm{~mm}$ was found not to impair mitochondrial function (data not shown).

Increased levels of oxidative stress and overactivation of glutamate receptors may contribute to the pathogenesis of several neurodegenerative conditions associated with increased homocysteine levels including stroke (Dirnagl et al., 1999) and Alzheimer's disease (Mattson et al., 1999). To determine whether homocysteine might render neurons vulnerable to oxidative stress and excitotoxicity, we exposed hippocampal neurons to homocysteine alone or in combination with oxidative $\left(\mathrm{Fe}^{2+}, \mathrm{Cu}^{2+}\right.$, and 4-hydroxynonenal) or excitotoxic (glutamate) insults and then quantified apoptotic neurons $24 \mathrm{hr}$ later. We chose concentrations of these insults that alone did not significantly increase neuronal apoptosis during the
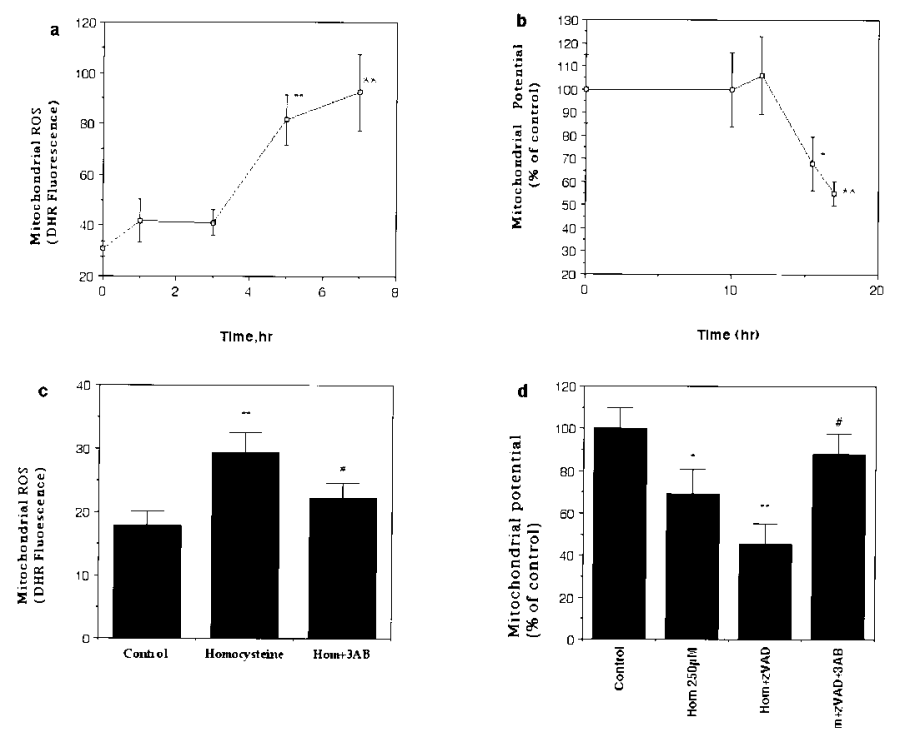

Figure 3. Homocysteine induces delayed mitochondrial oxidative stress and membrane depolarization that require PARP activation. $a$, Levels of mitochondrial reactive oxygen species (ROS; DHR fluorescence) were measured in hippocampal neurons at the indicated time points after exposure to $250 \mu \mathrm{M}$ homocysteine. ${ }^{* *} p<0.01$ compared with the basal value. $b$, Mitochondrial transmembrane potential (JC-1 fluorescence) was measured in hippocampal neurons at the indicated time points after exposure to 250 $\mu \mathrm{M}$ homocysteine. ${ }^{*} p<0.05$ and $* * p<0.01$ compared with the basal value. $c$, Levels of mitochondrial $\operatorname{ROS}$ were measured $5 \mathrm{hr}$ after exposure to 250 $\mu \mathrm{M}$ homocysteine in neurons in control cultures and cultures pretreated for 1 hr with $5 \mathrm{~mm} 3 \mathrm{AB}$. ** $p<0.01$ compared with the control value; $\# p<0.05$ compared with the value for cultures exposed to homocysteine alone. $d$, Mitochondrial transmembrane potential was measured $18 \mathrm{hr}$ after exposure to $250 \mu \mathrm{M}$ homocysteine in neurons in control cultures and cultures pretreated for $1 \mathrm{hr}$ with $10 \mu \mathrm{M}$ zVAD-fmk alone or in combination with $5 \mathrm{~mm}$ $3 \mathrm{AB} .{ }^{*} p<0.05$ and ${ }^{*} p<<0.01$ compared with the control value; $\# p<0.01$ compared with the value for cultures exposed to Hom $+z V A D$. For each graph $(a-d)$ the values are the mean and SD of determinations made in four to six cultures; statistical comparisons used ANOVA with Scheffe post hoc tests.

exposure period. Homocysteine sensitized neurons to death induced by each of the oxidative insults and by glutamate (Fig. $4 a$ ). The increased vulnerability of homocysteine-treated hippocampal neurons to excitotoxicity was associated with perturbed $\mathrm{Ca}^{2+}$ homeostasis, as indicated by an elevation of basal intracellular $\mathrm{Ca}^{2+}$ concentration and an enhanced $\mathrm{Ca}^{2+}$ response to glutamate (Fig. $4 b)$. Treatment of neurons with $3 \mathrm{AB}$ primarily prevented the elevation of intracellular $\mathrm{Ca}^{2+}$ levels induced by homocysteine. In neurons exposed to $250 \mu \mathrm{M}$ homocysteine for $5 \mathrm{hr}$ the $\mathrm{Ca}^{2+}$ level was $207 \pm 17 \%$ of that of the saline-treated control cultures, in neurons exposed to $5 \mathrm{~mm} 3 \mathrm{AB}$ plus $250 \mu \mathrm{M}$ homocysteine for $5 \mathrm{hr}$ the $\mathrm{Ca}^{2+}$ level was $117 \pm 26 \%$ of the control level $(p<0.002$ compared with homocysteine alone), and in neurons exposed to 5 mM $3 \mathrm{AB}$ alone for $5 \mathrm{hr}$ the $\mathrm{Ca}^{2+}$ level was $64 \pm 20 \%$ of the control level (values are mean \pm SD of determinations made in six cultures; 20-35 neurons analyzed/culture). In addition, treatment of neurons with the NMDA receptor antagonist MK-801 and the intracellular $\mathrm{Ca}^{2+}$ chelator BAPTA AM significantly attenuated neuronal death induced by homocysteine alone or in combination with glutamate (data not shown).

To determine whether increased levels of homocysteine modify neuronal vulnerability to excitotoxicity in vivo, we infused either homocysteine alone or in combination with the seizure-inducing excitotoxin kainate into the dorsal hippocampus of adult mice. Although homocysteine alone did not damage hippocampal neurons, it markedly exacerbated kainate-induced damage to CA3 pyramidal neurons (Fig. $4 c, d$ ). In the present experiments, in which the mice were killed $24 \mathrm{hr}$ after kainate administration, there was no loss of CA1 neurons under any of the experimental conditions (data not shown). 

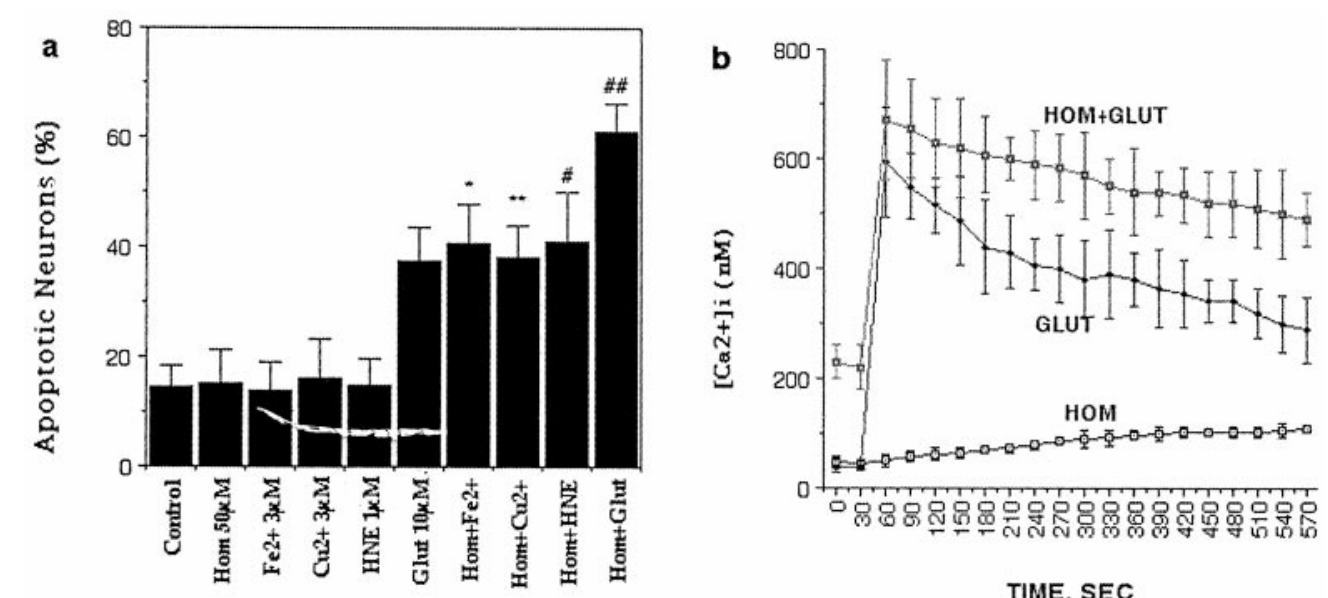

c
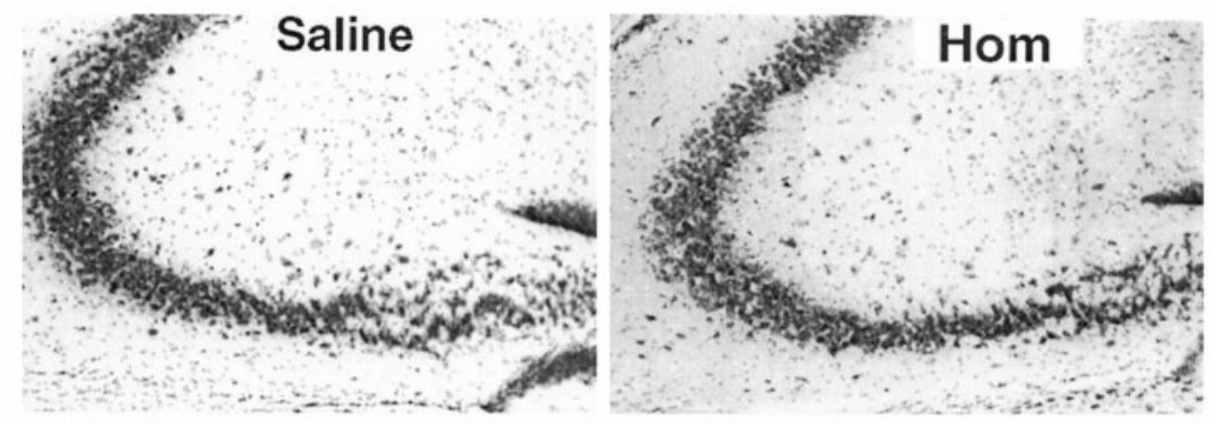

pocampal neurons to excitotoxicity and oxidative injury. $a$, Cultures were exposed for $30 \mathrm{hr}$ to the indicated treatments, and the percentages of neurons with apoptotic nuclei were quantified. Values are the mean and SD of determinations made in four to six cultures. ${ }^{*} p<0.01$ and ${ }^{* *} p<$ 0.001 compared with the corresponding value for cultures exposed to the oxidative insult or glutamate (Glut) alone (ANOVA with Scheffe post hoc tests). $b$, Levels of intracellular free $\mathrm{Ca}^{2+}$ were measured at baseline and after exposure to $100 \mu \mathrm{M}$ glutamate. Cultures were pretreated for 1 hr with vehicle (Glut) or $250 \mu \mathrm{M}$ homocysteine $(\mathrm{Hom}+\mathrm{Glut})$ before exposure to glutamate. Additional cultures were exposed to $250 \mu \mathrm{M}$ homocysteine $30 \mathrm{sec}$ after the initial measurement of basal levels of $\mathrm{Ca}^{2+} . c$, Cresyl violet-stained brain sections show the $\mathrm{CA} 3$ and hilar region of hippocampi from mice that had received an intrahippocampal injection of the indicated treatments $24 \mathrm{hr}$ previously (kainate, $0.2 \mu \mathrm{g}$; homocysteine, $4.3 \mathrm{ng}$ ). Note the modest damage to CA3 neurons in the mouse administered kainate alone and the greatly enhanced damage to CA3 and hilar neurons in the mouse receiving homocysteine plus kainate. $d$, Mice received intrahippocampal injections of the indicated treatments. Twenty-four hours later mice were killed, and the percentages of undamaged neurons in region $\mathrm{CA} 3$ of the hippocampus were quantified. Values are the mean and SD of determinations made in six to eight mice. $h d$, High dose; $H N E$, 4-hydroxynonenal; $K A$, kainate; $l d$, low dose. ${ }^{*} p<0.01$ versus saline; $* * p<$ 0.01 and $* * * p<0.001$ versus Homhd.
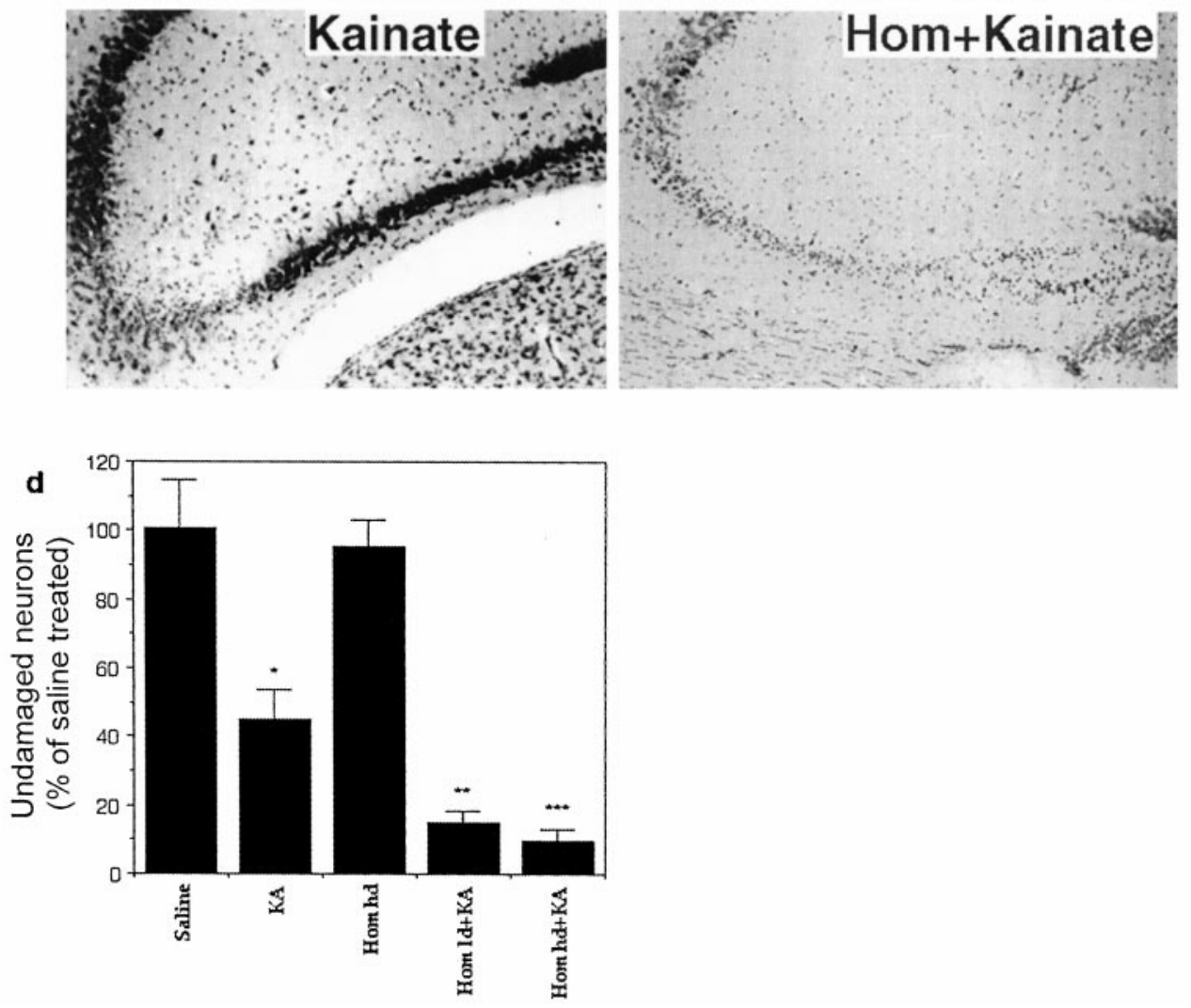

\section{DISCUSSION}

The events in the apoptotic pathway activated by homocysteine appear to be ordered as follows: DNA damage, PARP activation, caspase activation and p53 activation, mitochondrial membrane potential decline, and nuclear disintegration. We found that inhibition of PARP primarily suppressed homocysteine-induced increases of levels of p53, intracellular calcium, reactive oxygen species, and caspase activation and also attenuated the decline in mitochondrial membrane potential. Our data do not establish whether NAD/ATP depletion can account for the entire cascade of PARP-mediated neurodegenerative events triggered by homocysteine, and further studies in which the energy pathways are selectively manipulated will be required to address this important issue. Interestingly, caspase activation preceded mitochondrial mem- 
brane depolarization in the cascade of events induced by homocysteine. One possible explanation for this temporal ordering is that membrane depolarization occurs after cytochrome $\mathrm{c}$ release and caspase- 3 activation; this would be consistent with recent studies showing that cytochrome c can be released without detectable depolarization of the mitochondrial membrane (Bossy-Wetzel et al., 1998; Krohn et al., 1999). A second possibility is that premitochondrial caspases (Steemans et al., 1998) might be activated in neurons exposed to homocysteine. A role for p53 in homocysteine-induced, PARP-mediated neuronal apoptosis is consistent with considerable data implicating p53 in neuronal deaths that occur in experimental models of excitotoxic and ischemic brain injury (Sakhi et al., 1996; McGahan et al., 1998; Xiang et al., 1998).

Previous studies have shown that homocysteine is rapidly taken up by neurons via a specific membrane transporter (Grieve et al., 1992), a mechanism that results in accumulation of relatively high concentrations of homocysteine within the cell. Increased levels of homocysteine in the nucleus of cells may induce DNA strand breaks by disturbing the DNA methylation cycle (Blount et al., 1997). In agreement with previous studies of the actions of PARP in cell deaths resulting from DNA damage in non-neuronal cells (Nosseri et al., 1994), we found that inhibition of PARP protected neurons against both apoptosis and necrosis. On the other hand, suppression of PARP cleavage by treatment of neurons with the caspase inhibitor zVAD-fmk shifted the mode of cell death from apoptosis to necrosis, although our data do not exclude the possibility that, under these conditions, homocysteine can kill neurons by a caspase-independent apoptotic mechanism. These results support a model in which caspase-mediated cleavage of PARP prevents ATP depletion, thereby allowing the energy-dependent steps required for apoptosis. It was reported recently that basal levels of PARP activity are greater in neurons than in glia and, within the hippocampus, are greater in dentate neurons than in pyramidal neurons (Pieper et al., 2000). The latter study also showed that PARP is activated in response to glutamate receptor stimulation, suggesting that differential activation of PARP under excitotoxic conditions may contribute greatly to selective neuronal vulnerability. Consistent with the latter findings, our data suggest a major role for PARP activation in homocysteine-induced neuronal apoptosis and increased neuronal vulnerability to excitotoxicity.

Neurons have been shown to be more vulnerable to DNA damage than have other cell types. For example, mouse neuroblastoma cells become extremely sensitive to ultraviolet radiation-induced apoptosis after terminal differentiation (McCombe et al., 1976), and neurons are more vulnerable to $\gamma$-irradiation than are astrocytes (Gueneau et al., 1979). We have found that cultured hippocampal neurons are much more vulnerable to homocysteine than are cultured vascular endothelial cells or astrocytes; the latter cell types are not killed by homocysteine concentrations up to $10 \mathrm{~mm}$ during a $48 \mathrm{hr}$ exposure period (I. Kruman and M. P. Mattson, unpublished data). This is in agreement with a previous study showing that millimolar concentrations of homocysteine are not toxic to endothelial cells (Outinen et al., 1998). Although it is not known how homocysteine sensitizes neurons to oxidative stress and excitotoxicity, one possibility is that the mechanism involves oxidation of its sulfhydryl group, resulting in production of superoxide and hydrogen peroxide (Wall et al., 1980; Starkebaum and Harlan, 1986; Blundell et al., 1996). Our data suggest that a DNA damage response is an early event in the apoptotic cascade induced by homocysteine. However, additional adverse effects on neuronal physiology may also contribute to the neurotoxic actions of homocysteine. For example, it was reported that homocysteine is a partial agonist at the NMDA receptor (Lipton et al., 1997).

The normal range of homocysteine concentrations in plasma is 5-15 $\mu \mathrm{M}$, and levels of homocysteine in CSF and brain tissue are reported to range from 0.5 to $10 \mu \mathrm{M}$ (Welch and Loscalzo, 1998). In patients with inherited hyperhomocysteinemia, plasma homocysteine levels reach millimolar concentrations, and CSF levels are elevated into the low micromolar range (Surtees et al., 1997). We found that concentrations of homocysteine as low as $0.5 \mu \mathrm{M}$ can induce apoptosis of cultured hippocampal neurons and that homocysteine is particularly effective in sensitizing neurons to excitotoxicity, both in cell culture and in vivo. These findings suggest that an endangering action of homocysteine damage may underlie its adverse effects on neurons in the brains of patients with hyperhomocysteinemia. Levels of plasma homocysteine have been found to increase with age (Andersson et al., 1992; Brattstrom et al., 1994), possibly as a result of age-related impairment of renal function or a decline in cystathionine $\beta$-synthase activity (Meleady and Graham, 1998). Moreover, elevated levels of homocysteine are associated with an increased risk for stroke (Elkind and Sacco, 1998) and Alzheimer's disease (Clarke et al., 1998). The latter disorders involve increased oxidative stress and overactivation of glutamate receptors (Mattson, 1997; Dirnagl et al., 1999). Our experimental data showing that homocysteine can sensitize neurons to such adverse age-related conditions suggest a mechanism by which homocysteine might contribute to the pathogenesis of neurodegenerative disorders and further suggest a mechanism by which dietary folate may reduce the risk for these disorders (Selhub et al., 2000).

\section{REFERENCES}

Adamec E, Vonsattel JP, Nixon RA (1999) DNA strand breaks in Alzheimer's disease. Brain Res 849:67-77.

Andersson A, Brattstrom L, Israelsson B, Isaksson A, Hamfelt A, Hultberg B (1992) Plasma homocysteine before and after methionine loading with regard to age, gender, and menopausal status. Eur J Clin Invest 22:79-87.

Bernofsky C, Swan M (1973) An improved cycling assay for nicotinamide adenine dinucleotide. Anal Biochem 53:452-460.

Blount BC, Mack MM, Wehr CM, MacGregor JT, Hiatt RA, Wang G, Wickramasinghe SN, Everson RB, Ames BN (1997) Folate deficiency causes uracil misincorporation into human DNA and chromosome breakage: implication for cancer and neuronal damage. Proc Natl Acad Sci USA 94:3290-3295.

Blundell G, Jones BG, Rose FA, Tudball N (1996) Homocysteine mediated endothelial cell toxicity and its amelioration. Atherosclerosis 122: 163-172.

Bossy-Wetzel E, Newmeyer DD, Green DR (1998) Mitochondrial cytochrome c release in apoptosis occurs upstream of DEVD-specific caspase activation and independently of mitochondrial transmembrane depolarization. EMBO J 17:37-49.

Bozner P, Grishko V, LeDoux SP, Wilson GL, Chyan YC, Pappolla MA (1997) The amyloid $\beta$ protein induces oxidative damage of mitochondrial DNA. J Neuropathol Exp Neurol 56:1356-1362.

Brattstrom L, Lindgren A, Israelsson B, Andersson A, Hultberg B (1994) Homocysteine and cysteine: determinants of plasma levels in middle aged and elderly subjects. J Intern Med 236:633-641.

Bruce AJ, Boling W, Kindy MS, Peschon J, Kraemer PJ, Carpenter MK, Holtsberg FW, Mattson MP (1996) Altered neuronal and microglial responses to brain injury in mice lacking TNF receptors. Nat Med 2:788-794.

Cheng B, Christakos S, Mattson MP (1994) Tumor necrosis factors protect neurons against excitotoxic/metabolic insults and promote maintenance of calcium homeostasis. Neuron 12:139-153.

Clarke R, Smith AD, Jobst KA, Refsum H, Sutton L, Ueland PM (1998) Folate, vitamin B12, and serum total homocysteine levels in confirmed Alzheimer disease. Arch Neurol 55:1449-1455.

Cregan SP, MacLaurin JG, Craig CG, Robertson GS, Nicholson DW, Park DS, Slack RS (1999) Bax-dependent caspase-3 activation is a key determinant in p53-induced apoptosis in neurons. J Neurosci 19:7860-7869.

de la Monte SM, Sohn YK, Ganju N, Wands JR (1998) P53- and CD95associated apoptosis in neurodegenerative diseases. Lab Invest 78:401-411.

Dirnagl U, Iadecola C, Moskowitz MA (1999) Pathobiology of ischaemic stroke: an integrated view. Trends Neurosci 22:391-397.

Elkind MS, Sacco RL (1998) Stroke risk factors and stroke prevention. Semin Neurol 18:429-440.

Finkelstein JD (1990) Methionine metabolism in mammals. J Nutr Biochem 1:228-237.

Furukawa K, Mattson MP (1998) The transcription factor NF- $\kappa$ B mediates increases in calcium currents and decreases in NMDA and AMPA/ kainate-induced currents in response to $\mathrm{TNF} \alpha$ in hippocampal neurons. J Neurochem 70:1876-1886.

Giles WH, Kittner SJ, Anda RF, Croft JB, Casper ML (1995) Serum folate and risk for ischemic stroke. First National Health and Nutrition Examination Survey epidemiologic follow-up study. Stroke 26:1166-1170.

Grieve A, Butcher SP, Griffiths R (1992) Synaptosomal plasma membrane transport of excitatory sulphur amino acid transmitter candidates: kinetic characterisation and analysis of carrier specificity. J Neurosci Res 32: 60-68.

Gueneau G, Drouet J, Privat A, Court L (1979) Differential radiosensitiv- 
ity of neurons and neuroglia of the hippocampus in the adult rabbit. Acta Neuropathol (Berl) 48:199-209.

Guo Q, Sebastian L, Sopher BL, Miller MW, Glazner GW, Ware CB, Martin GM, Mattson MP (1999) Neurotrophic factors [activitydependent neurotrophic factor (ADNF) and basic fibroblast growth factor (bFGF)] interrupt excitotoxic neurodegenerative cascades promoted by a PS1 mutation. Proc Natl Acad Sci USA 96:4125-4130.

Hinshaw DB, Lodhi IJ, Hurley LL, Atkins KB, Dabrowska MI (1999) Activation of poly[ADP-ribose]polymerase in endothelial cells and keratinocytes: role in an in vitro model of sulfur mustard-mediated vesication. Toxicol Appl Pharmacol 156:17-29.

Hou ST, Tu Y, Buchan AM, Huang Z, Preston E, Rasquinha I, Robertson GS, MacManus JP (1997) Increases in DNA lesions and the DNA damage indicator Gadd45 following transient cerebral ischemia. Biochem Cell Biol 75:383-392.

Houser CR (1999) Neuronal loss and synaptic reorganization in temporal lobe epilepsy. Adv Neurol 79:743-761.

Hughes PE, Alexi T, Schreiber SS (1997) A role for the tumour suppressor gene p53 in regulating neuronal apoptosis. NeuroReport 8:v-xii.

Johnson MD, Kinoshita Y, Xiang H, Ghatan S, Morrison RS (1999) Contribution of p53-dependent caspase activation to neuronal cell death declines with neuronal maturation. J Neurosci 19:2996-3006.

Keller JN, Kindy MS, Holtsberg FW, St Clair DK, Yen HC, Germeyer A, Steiner SM, Bruce-Keller AJ, Hutchins JB, Mattson MP (1998) Mitochondrial MnSOD prevents neural apoptosis and reduces ischemic brain injury: suppression of peroxynitrite production, lipid peroxidation and mitochondrial dysfunction. J Neurosci 18:687-698.

Krohn AJ, Wahlbrink T, Prehn JH (1999) Mitochondrial depolarization is not required for neuronal apoptosis. J Neurosci 19:7394-7404.

Kruman I, Bruce-Keller AJ, Bredesen DE, Waeg G, Mattson MP (1997) Evidence that 4-hydroxy nonenal mediates oxidative stress-induced neuronal apoptosis. J Neurosci 17:5089-5100.

Lazebnik YA, Kaufmann SH, Desnoyers S, Poirier GG, Earnshaw WC (1994) Cleavage of poly(ADP-ribose) polymerase by a proteinase with properties like ICE. Nature 371:346-347.

Linnik MD, Zobrist RH, Hatfield MD (1993) Evidence supporting a role for programmed cell death in focal cerebral ischemia in rats. Stroke 24:2002-2008.

Lipton SA, Kim WK, Choi YB, Kumar S, D'Emilia DM, Rayudu PV, Arnelle DR, Stamler JS (1997) Neurotoxicity associated with dual actions of homocysteine at the $N$-methyl-D-aspartate receptor. Proc Natl Acad Sci USA 94:5923-5928.

Love S, Barber R, Wilcock GK (1998) Apoptosis and expression of DNA repair proteins in ischaemic brain injury in man. NeuroReport 9:955-959.

Mattson MP (1997) Cellular actions of b-amyloid precursor protein and its soluble and fibrillogenic derivatives. Physiol Rev 77:1081-1132.

Mattson MP, Murrain M, Guthrie PB, Kater SB (1989) Fibroblast growth factor and glutamate: opposing actions in the generation and degeneration of hippocampal neuroarchitecture. J Neurosci 9:3728-3740.

Mattson MP, Goodman Y, Luo H, Fu W, Furukawa K (1997) Activation of NF- $\kappa$ B protects hippocampal neurons against oxidative stress-induced apoptosis: evidence for induction of Mn-SOD and suppression of peroxynitrite production and protein tyrosine nitration. J Neurosci Res 49:681-697.

Mattson MP, Keller JN, Begley JG (1998) Evidence for synaptic apoptosis. Exp Neurol 153:35-48.

Mattson MP, Pedersen WA, Duan W, Culmsee C, Camandola S (1999) Cellular and molecular mechanisms underlying perturbed energy metabolism and neuronal degeneration in Alzheimer's and Parkinson's diseases. Ann NY Acad Sci 893:154-175.

McCombe P, Lavin M, Kidson C (1976) Control of DNA repair linked to neuroblastoma differentiation. Int J Radiat Biol Relat Stud Phys Chem Med 29:523-531.

McGahan L, Hakim AM, Robertson GS (1998) Hippocampal Myc and p53 expression following transient global ischemia. Mol Brain Res 56:133-145.

Meleady RA, Graham IM (1998) Homocysteine and vascular disease: nature or nurture? J Cardiovasc Risk 5:233-237.

Miller JW (1999) Homocysteine and Alzheimer's disease. Nutr Rev $57: 126-129$.
Morris EJ, Dreixler JC, Cheng K-Y, Wilson PM, Gin RM, Geller HM (1999) Optimization of single-cell gel electrophoresis (SCGE) for quantitative analysis of neuronal DNA damage. Biotechniques 26:282-289.

Morrison JH, Hof PR (1997) Life and death of neurons in the aging brain. Science 278:412-419.

Nicotera P, Ankarcrona M, Bonfoco E, Orrenius S, Lipton SA (1997) Neuronal necrosis and apoptosis: two distinct events induced by exposure to glutamate or oxidative stress. Adv Neurol 72:95-101.

Nosseri C, Coppola S, Ghibelli L (1994) Possible involvement of poly(ADP-ribosyl) polymerase in triggering stress-induced apoptosis. Exp Cell Res 212:367-373.

Outinen PA, Sood SK, Liaw PCY, Sarge KD, Maeda N, Hirsh J, Ribau J, Podor TJ, Weitz JI, Austin RC (1998) Characterization of the stressinducing effects of homocysteine. Biochem J 332:213-221.

Pieper AA, Verma A, Zhang J, Snyder SH (1999) Poly (ADP-ribose) polymerase, nitric oxide and cell death. Trends Pharmacol Sci 20:171-181.

Pieper AA, Blackshaw S, Clements EE, Brat DJ, Krug DK, White AJ, Pinto-Garcia P, Favit A, Conover JR, Snyder SH, Verma A (2000) Poly(ADP-ribosyl)ation basally activated by DNA strand breaks reflects glutamate-nitric oxide neurotransmission. Proc Natl Acad Sci USA 97:1845-1850.

Refsum H, Ueland PM, Nygard O, Vollset SE (1998) Homocysteine and cardiovascular disease. Annu Rev Med 49:31-62.

Sakhi S, Sun N, Wing LL, Mehta P, Schreiber SS (1996) Nuclear accumulation of p53 protein following kainic acid-induced seizures. NeuroReport 7:493-496.

Scott JM, Weir DG (1998) Folic acid, homocysteine and one-carbon metabolism: a review of the essential biochemistry. J Cardiovasc Risk 5:223-227.

Selhub J, Bagley LC, Miller J, Rosenberg IH (2000) B vitamins, homocysteine, and neurocognitive function in the elderly Am J Clin Nutr 71:S614-S620.

Squire LR, Zola SM (1996) Ischemic brain damage and memory impairment: a commentary. Hippocampus 6:546-552.

Starkebaum G, Harlan JM (1986) Endothelial cell injury due to coppercatalyzed hydrogen peroxide generation from homocysteine. J Clin Invest 77:1370-1376.

Steemans M, Goossens V, Van de Craen M, Van Herreweghe F, Vancompernolle K, De Vos K, Vandenabeele P, Grooten J (1998) A caspaseactivated factor (CAF) induces mitochondrial membrane depolarization and cytochrome c release by a nonproteolytic mechanism. J Exp Med 188:2193-2198.

Su JH, Anderson AJ, Cummings B, Cotman CW (1994) Immunocytochemical evidence for apoptosis in Alzheimer's disease. NeuroReport 5:2529-2533.

Surtees R, Bowron A, Leonard J (1997) Cerebrospinal fluid and plasma total homocysteine and related metabolites in children with cystathionine $\beta$-synthase deficiency: the effect of treatment. Pediatr Res 42:577-582.

Torp R, Su JH, Deng G, Cotman CW (1998) GADD45 is induced in Alzheimer's disease, and protects against apoptosis in vitro. Neurobiol Dis 5:245-252.

van den Berg M, van der Knaap MS, Boers GH, Stehouwer CD, Rauwerda JA, Valk J (1995) Hyperhomocysteinaemia; with reference to its neuroradiological aspects. Neuroradiology 37:403-411.

Wall RT, Harlan JM, Harker LA, Striker GE (1980) Homocysteineinduced endothelial cell injury in vitro: a model for the study of vascular injury. Thromb Res 18:113-121.

Watkins D, Rosenblatt DS (1989) Functional methionine synthase deficiency (cblE and cblG): clinical and biochemical heterogeneity. Am J Med Genet 34:427-434.

Welch GN, Loscalzo J (1998) Homocysteine and atherothrombosis. N Engl J Med 338:1042-1050.

White JR, Reynolds IJ (1996) Mitochondrial depolarization in glutamatestimulated neurons: an early signal specific to excitotoxin exposure. J Neurosci 16:5688-5697.

Xiang H, Kinoshita Y, Knudson CM, Korsmeyer SJ, Schwartzkroin PA, Morrison RS (1998) Bax involvement in p53-mediated neuronal cell death. J Neurosci 18:1363-1373. 